\title{
Citizen Science in the Field: Co-experimentation at Pilot Scale for Sustainable Use of Natural Resources
}

\author{
Rosana Maria Kral ${ }^{1, *(\mathbb{D} \text {, Rizki Maftukhah }}{ }^{2,3}$, Axel Mentler ${ }^{3}$, Murtiningrum Murtiningrum ${ }^{2}$, \\ Ngadisih Ngadisih $^{2}$ and Katharina Maria Keiblinger ${ }^{3}$ (B) \\ 1 Department of Sustainable Agricultural Systems, Institute for Development Research, University of Natural \\ Resources and Life Sciences, 1190 Vienna, Austria \\ 2 Department of Agricultural and Biosystem Engineering, Faculty of Agricultural Technology, \\ Universitas Gadjah Mada, Yogyakarta 55281, Indonesia; maftukhah.rizki@mail.ugm.ac.id (R.M.); \\ tiningm@ugm.ac.id (M.M.); ngadisih@ugm.ac.id (N.N.) \\ 3 Department of Forest and Soil Sciences, Institute of Soil Research, University of Natural Resources and Life \\ Sciences, 1190 Vienna, Austria; axel.mentler@boku.ac.at (A.M.); katharina.keiblinger@boku.ac.at (K.M.K.) \\ * Correspondence: rosana.kral@boku.ac.at; Tel.: +43-1-47654-93412
}

Received: 30 July 2020; Accepted: 14 September 2020; Published: 17 September 2020

\begin{abstract}
Natural resource management is a cross-sectoral topic, as reflected by its inclusion in several of the United Nations Sustainable Development Goals (e.g., SDGs 2, 6, 12, 15). In the study area on Bangka Island, Indonesia, agriculture is a pillar of local food security and livelihoods, making restoration of degraded lands also a local issue. The present study aims at restoring degraded land after tin mining and at restoring the natural soil base rendering it more suitable for agriculture. We use co-experimentation with citizens as a tool to develop options for re-habilitation at a pilot scale. The recruitment process in this study was reversed insofar as local citizens were at the origin of the project idea. Consequently, buy-in was high among local stakeholders. This set to increase the probability of successfully scaling up effective and actionable practices that were developed during co-experimentation at both local and regional levels. Co-experimentation provided a platform for exchange between local citizens and scientists. Citizens did not need to learn new skills to be able to participate in the scientific process and could autonomously evaluate results. We see involvement of citizens in this type of scientific projects not only as feasible, but as rewarding for all involved partners and as beneficial for the project outcomes. In light of the call for partnerships to achieve the Sustainable Development Goals, we can only recommend investing in communication and relationship building to work together on better solutions to the challenges we face.
\end{abstract}

Keywords: co-experimentation; co-creation; citizen science; participation; soil re-habilitation; soil amendments; community development; tin mining; transdisciplinary research

\section{Introduction}

Bangka Island lies in the South East Asian tin belt. The Indonesian island is famous for two export goods: high-quality pepper that is valued by gourmet restaurants around the world and tin that is used in the electronics industry. Indonesia mines around $25-30 \%$ of the world's tin production [1], and $70 \%$ of the island's area is or was used for mining [2]. However, several challenges lie ahead: tin reserves are declining, and mining has dire consequences for the island's ecosystem and agricultural production [3,4].

Illegal mining is common on the island: since tin can be gained from near-surface deposits and without chemicals, the only infrastructure needed are pumps to mix the soil with water; subsequent density fractionation then separates cassiterite (a fine-sand fraction) from the quartz 
sand and kaolinite. Tin is later thermally extracted from the cassiterite. The main by-products, kaolinite and quartz sand, are deposited indiscriminately in the surrounding areas of the mining sites. The kaolinite deposits lead to water logging of soils, and when it rains, ponds develop rapidly. Moreover, the quartz sand deposits exhibit extremely high infiltration rates and lack water retention capacity and nutrients. These phenomena severely hamper plant growth and render agriculture challenging, especially achieving acceptable crop yields.

Since tin mining is becoming less and less profitable, the regional government places agriculture and tourism at the heart of its development plans $[5,6]$. In addition to creating employment opportunities, the agricultural sector was targeted in order to reduce the island's dependency on food imports from other, larger islands. However, agriculture is a difficult livelihood strategy, since the soils are left dysfunctional by tin mining. Both of the above strategies, agriculture and tourism, rely on soil-related ecosystem services to support human activities and infrastructure: one aspect is that soil provides for food and fiber, filtering of nutrients and contaminants; the other perspective is that soil-supported ecosystems provide recreational opportunities, harbor cultural heritage and provide soothing aesthetics [7-10]. If agriculture is to provide a viable livelihood option for Bangka islanders, it is imperative to restore ex-mining lands and render them conducive to food production once more.

Currently, around 10,000 ha of such formerly mined areas are scheduled for re-habilitation [5]. Innovative re-habilitation solutions that are adapted to the local socio-economic situation are needed. Both local government and mining companies have the mandate to work towards soil re-habilitation. The local government issues master plans for agricultural development, and the governor can define target areas for preferential re-habilitation activities mediated through extension services (Department of Agriculture). Mining companies, most of which are state-owned, can obtain permission for tin exploitation from the Ministry of Energy and Mineral Resources (Kementerian Energi Dan Sumber Daya Mineral), but are required to submit re-habilitation plans covering the entire mining process and post-mining stages, as well as deposit funds to finance these activities after the end of mining operations [11]. While the companies have experience with re-habilitating land for forest development and are expanding their activities to marine ecosystems in offshore destinations, the demand for expertise in land re-habilitation for agriculture is still high.

Restoration of degraded lands and ecosystems is a central issue for the inhabitants of Bangka Island, but the need for restoration is also reflected in the United Nations Sustainable Development Goals (SDGs [12]), especially in those relating to the biosphere: SDG 6-providing clean water and sanitation, SDG 13-taking climate action, SDG 14-sustainable use of seas, and SDG 15-sustainable use of terrestrial ecosystems. The targets of SDG 15 specifically mention the need to restore degraded land and soil (SDG 15.3). Since natural resource management (NRM) is a cross-sectoral topic, it also figures prominently among many of the SDGs that are less obviously connected to the biosphere. For the smallholder farmers on Bangka, restoring the degraded lands is the first step towards reviving their natural resources, using them more sustainably and efficiently (SDG 12.2); through re-habilitating degraded soils, water use efficiency will be equally addressed and improved (SDG 6.3). However, soil re-habilitation for agricultural use will also (i) contribute to food security by increasing agricultural productivity (SDG 2.3), and (ii) render food production systems more sustainable (SDG 2.4). Since restored lands are crucial for the livelihoods of locals, re-habilitating soils on Bangka island has the potential to further feed into efforts to reduce poverty (SDG1).

As stressed in SDGs 2.3 and 2.4, we firmly believe that making food production systems more sustainable and resilient requires that smallholder farmers have access to knowledge. Still better than having access to knowledge that has been provided by somebody else is the chance to directly participate in knowledge generation: citizen science can be a powerful tool to co-create knowledge. There is a long history of citizen scientists being involved in biodiversity monitoring, especially in bird watching [13,14]. More recent examples of citizen involvement in scientific research include recordings of pests or invasive species, or recording or validation of climate data [15-18]. In the case presented 
herein, the aim of the study was to use co-experimentation to restore the natural resource (degraded soils), and to evaluate crops for cultivation on soils that are being freshly re-established.

Citizen science (CS) has great potential to connect agriculture and education, and especially community-based initiatives provide excellent opportunities to launch participatory projects [18]. However, if such projects are to be successful and contribute to reaching the SDGs, it is imperative to strengthen the collaboration and above all to promote approaches that are based on meaningful partnerships. The cross-cutting SDG 17 reflects this paramount role of partnerships for reaching all other SDGs.

\section{Conceptual Background}

\subsection{Citizen Science as a Tool for Research into Natural Resources Management and Agriculture}

Citizen science has been broadly defined as any research process in which scientists and volunteers work together on scientific questions [19]. There are different ways to do CS, involvement of a more general public can occur at selected stages or at every step of the research process, be they merely consultative or functional, to more collaborative or even transformative interactions, at both large or smaller local scales, that promote hands-on experience [20-22]. Citizen science has been described as essentially running along two strands: one aiming at democratizing science, and one aiming at collectively gathering, submitting, or analyzing large quantities of data [23].

There is a second body of literature dealing with the involvement of non-academic partners in scientific research, especially in the context of NRM, agriculture, and development in general: here, participatory approaches and so-called action research have a long-standing history [24-26]. Involving others rather than exclusively academic partners is crucial here, since sustaining agriculture means sustaining resources and processes at its base. Correspondingly, sustainable agriculture has been described as a perpetual process rather than a fixed model [25]. To render NRM more sustainable at the same time as improving livelihood options for smallholder farmers, interventions of any sort have to be tailored to local contexts. Whichever form such an intervention might take, be it technological advances, adjusted management options, or other, it is imperative to involve those who shall benefit from such an intervention in the creation process [27].

Citizen Science approaches partly overlap with participatory approaches and other activities [14] and are well positioned to be included in such research [18]. That is, if participation of "citizens" goes beyond data collection alone, and if there is a meaningful exchange, an opportunity for mutual learning between partners from academia and agriculture. Alan Irwin, who coined the term "citizen science" at the turn of the last millennium, claimed that (i) research should "assist the needs and concerns of citizens" [28] rather than being defined by power holders of the economic or political arena [29], and that (ii) knowledge generation could be a process developed and implemented by citizens themselves [29]. Irwin saw special value in the context-related knowledge of citizens, which was different from the knowledge generated in more formalized settings like academia [28]. Our motivation for taking part in the co-creation of the present study runs in the same vein.

The way we define CS is "doing science with (other) citizens" to address challenges together. This is to stress the partnership approach that we see as vital for the success of such projects; but it is also a reference to how merely two centuries ago, most scientists had other professions to be able to afford their studies [30]. Our two motivations for engaging in a study with non-academic partners are (i) to work towards democratization of science, and (ii) to achieve better results, i.e., increased applicability of solutions that have been tailored to the local context. If a research project aims at delivering applicable options for transformation of existing practices and producing robust results, it is necessary to do science with different stakeholders in a real-world setting ("ground truthing" [31]), and to involve these stakeholders as early as possible in the scientific process. By real-word setting, we do not want to imply that other disciplines or approaches are not real. Many studies are performed under tightly controlled lab or greenhouse conditions, and there are perfectly valid reasons to do so. However, 
lab and greenhouse conditions can be quite different from natural conditions that farmers experience in their fields, hindering easy transfer or adaptation of new practices and technologies. When referring to 'real-world setting' here, we would like to emphasize that we aim to maximize the applicability of our type of applied research to the conditions that farmers experience in their fields.

Having knowledge flow in both directions does not yet warrant calling a project 'citizen science' [18], but it opens up opportunities. Not only did we involve other partners than purely academic stakeholders in co-creating the project from the very beginning-we, the scientists, were the ones being involved from the beginning. This study can be seen as demand-driven [21], but demand is not-or not exclusively-on the planners' side: the involved smallholder farmers or citizen scientists have a vital stake in this scientific endeavor. Nothing we did in this project would have happened had it not been for the farmers involved in it and had there not been functional working relationships between (i) the farmers and local extension, (ii) local extension and national research and higher education, and (ii) national and international research. The diverse group that is now involved in the presented project has grown organically, which is surely different from approaches where volunteers are recruited on a large scale and often do not know of each other, let alone interact with each other in their research activities [23]. This entails challenges, as well as success factors that differ from those CS projects involving much larger crowds of citizen contributors at a remote basis.

The strength of the present approach lies to a larger extent in developing interventions or solutions that are tailored to the specific context, to the needs, prerequisites, capabilities, and available resources of locals/ stakeholders/ farmers [25,32], and less in data collection or validation at a large scale, or in increasing the cost-effectiveness of the project budget. This also implies that the citizens involved in the present study are vital partners for determining conditions of and for implementation of the described research. In this context, we propose co-experimentation with local stakeholders as the means of generating scientific knowledge. The described co-experimentation is particularly well-suited for the inclusion of smallholder farmers in the research process, since it (i) relies on a set of skills that farmers already have, (ii) uses familiar activities, and (iii) manages without add-on technology, lowering the threshold for farmers to enter the project. The value of this approach is further based on the jointly developed knowledge. Co-experimentation also provides a platform for core partners (farmers, scientists) to communicate in an informal setting. This approach allows for much more direct and open exchange than the more formalized settings (e.g., field days, workshops, trainings) that are routinely employed for knowledge sharing in the agricultural context.

\subsection{Co-creating an Applied Research Project as a Pilot for More Sustainable Use of Natural Resources}

The present study contributes to a larger research framework. The objectives underlying this research framework are illustrated in Figure 1; further, the scheme depicts which partners take the lead in specific packages of the research framework, according to their respective expertise.

The larger research framework addresses several issues (grey ellipsoids, Figure 1); however, only a subset of activities is the focus of the present article. This case study illustrates how CS can be approached making use of a joint field site as a research tool (strongly contoured white ellipsoid, left side, Figure 1). The field site allows us to test several options for making NRM more sustainable on a pilot scale under natural conditions with local partners. Those options that prove successful shall lead to tailored interventions for community development on a larger scale, which is the expertise of partners in the intermediate and outer layers (research station, local extension, see Figure 2). Outreach activities have been an integral part since the study's inception and link the project to teaching and public awareness raising. While the current focus of the larger research framework is on re-habilitating soil using amendments, other topics such as possible heavy metal contamination (food safety, expertise mostly with scientific partners, dark grey background in Figure 1) and contributions to income generation (expertise mostly with local research institute, light grey background in Figure 1) are likely to come into view in the nearer future. 


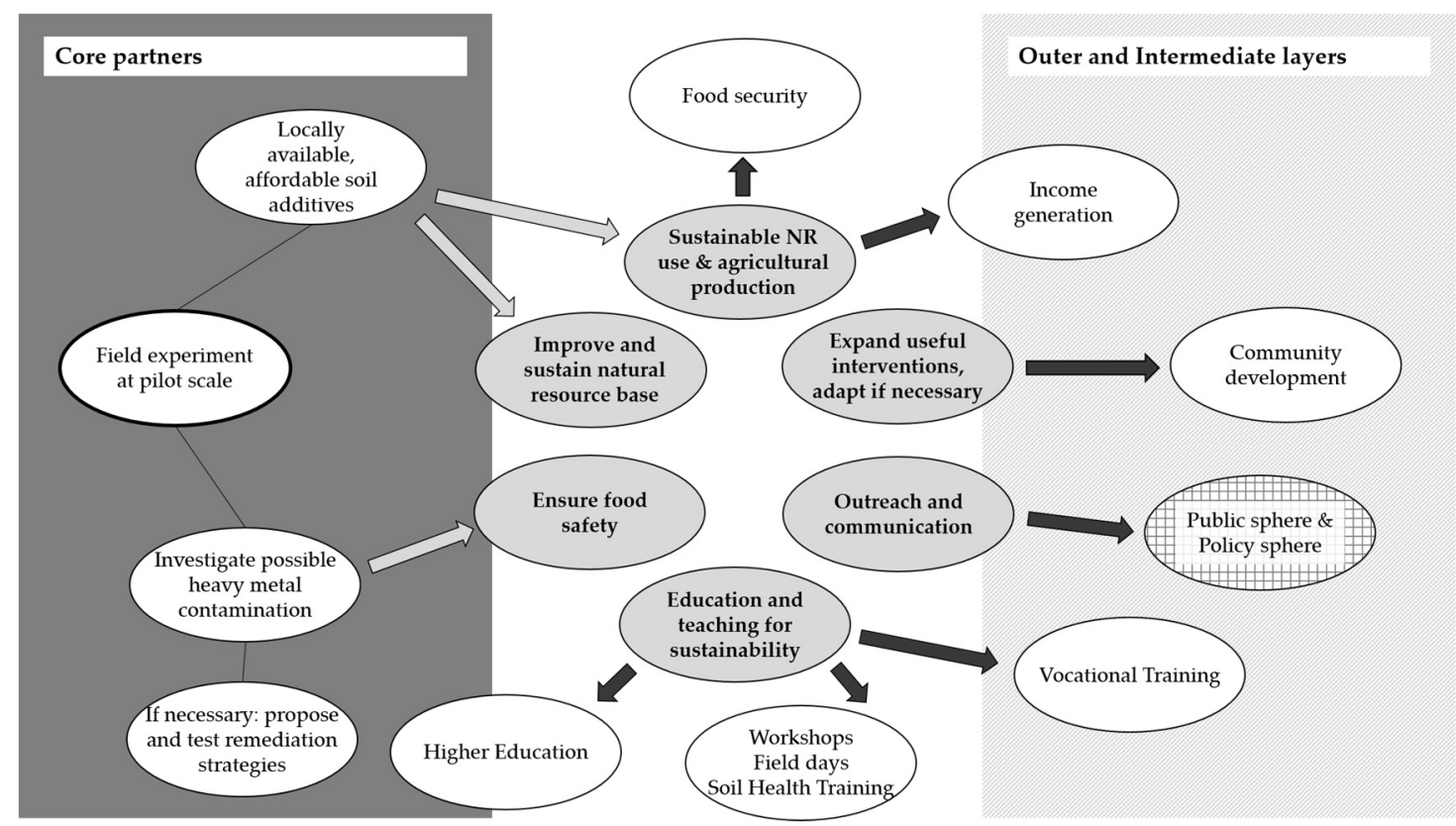

Figure 1. The wider objectives of the broader research project which are part of the concept are depicted in grey ellipsoids. The main underlying long-term goals (e.g., food security, community development) or measures to accomplish the objectives (e.g., field days, soil health training) are represented by white ellipsoids. The focus of the present study is improving the natural resource base and rendering the use of natural resources more sustainable via the research tool of a jointly developed experimental field site (strongly outlined ellipsoid, left). Arrows indicate which activities or achievements will inform other activities or achievements. Areas of expertise of partners in the larger research framework are represented by boxes in the background (dark grey to left side: core partners, light grey to right side: partners in intermediate and outer layers). For explanation of the partners involved, see following Figure 2 and text.

\section{Materials and Methods}

\subsection{Description of Study Site}

The study site is located on Bangka Island in the Java Sea; together with the neighboring island of Belitung, these two make up the province Bangka-Belitung, in the South East Asian tin belt. This Bangka Island is not to be confused with the like-named location in North Sulawesi, a diving hotspot in the Celebes Sea of the Western Pacific. The island of Bangka covers an area of $16,424 \mathrm{~km}^{2}$ and has a population of 1.46 million [33]. Of the economically active population, $30 \%$ work in agriculture, forestry, hunting, or fisheries, another $13 \%$ are employed in mining and quarrying [33]. Here, "economically active" is defined as follows: over 15 years of age, employed, actively looking for work or doing unpaid family work [33]. The number of individuals involved in any kind of mining activity is bound to be higher, since tin is frequently not only mined on large-scale, officially authorized industrial exploitation sites, but also on small, informal sites. Three large sectors contribute to the Gross Regional Domestic Product (GRDP): with 20.6\%, manufacturing is the largest contributor, followed by agriculture, forestry and fisheries (18.0\%), and mining and quarrying (10.6\%) [33]. Manufactured goods include products from vegetable oil and a wide array of products made from tin, underscoring the importance of both sectors, agriculture and mining, for the region's economy. Besides tin, Bangka island exports high-quality pepper worldwide, particularly white pepper, often traded as "Muntok white pepper" around the globe. 


\subsection{Partners in the Research Process}

Several local, national, and international stakeholders are involved in the research partnership. The partnerships in this study work in several layers (see Figure 2).

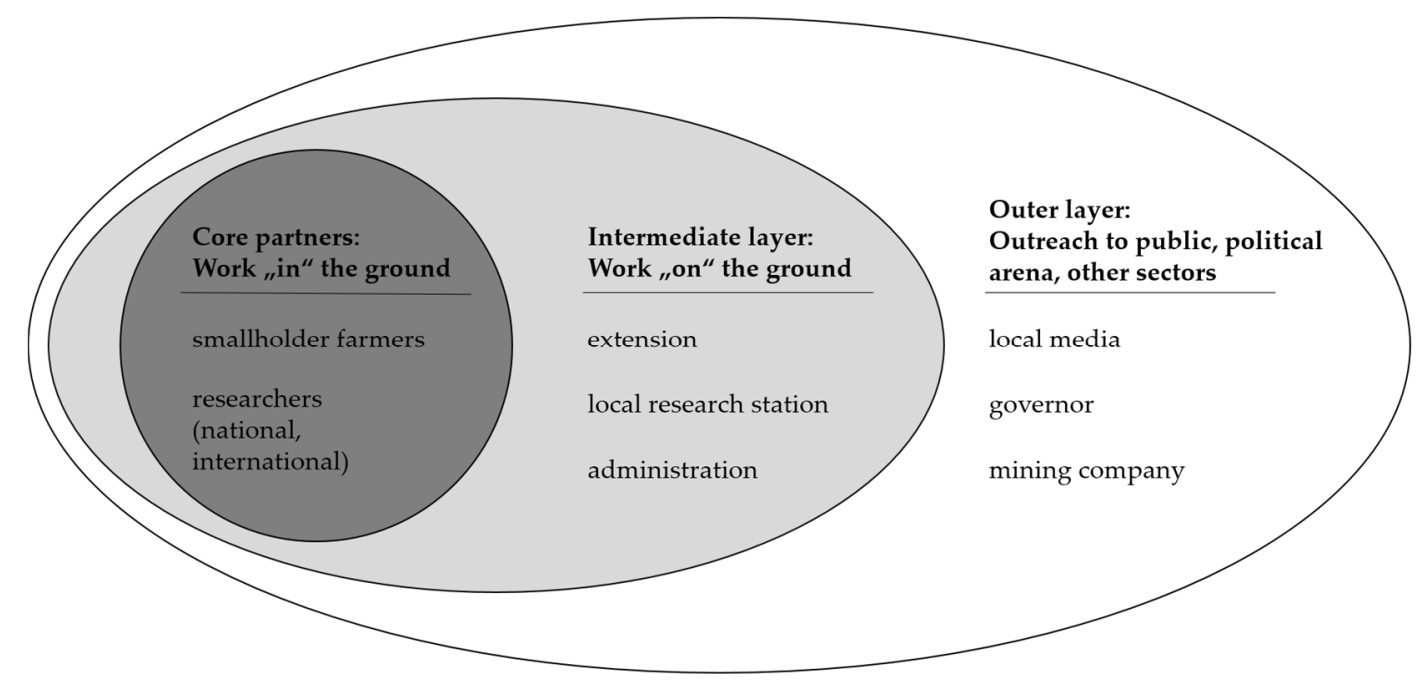

Figure 2. Various stakeholders are part of the research partnership. Smallholder farmers and researchers are at the core of the process (dark grey sphere). In the intermediate layer (light grey ellipsoid), extension, local applied research, as well as administration take part in the project process. The outer layer (white ellipsoid) supports links to the general public, the political arena, and other sectors that hold an interest in soil re-habilitation in the region.

At the innermost core of the project, local smallholder farmers and Indonesian, as well as Austrian researchers work towards restoring soil functions on formerly mined land. At the next level, this work "in" the ground is complemented by work "on" the ground with local extension, administration, and applied research. In the outer layers, there are contacts to other farmers and interested public (e.g., neighbors of the involved farmers, public visiting the experimentation site at their own instigation), district government (governor), the largest state-owned mining company (PT Timah), which is obliged by law to restore ex-mining land before returning it to local farmers, and local media.

While the core is instrumental in co-creating, implementing, and fine-tuning the project on the ground, the outer layer will be crucial for scaling out successful interventions in the near future. The intermediate layer has partly been vital to kick-start the project (extension), as well as to provide support and consultation. It is also the level at which (i) results from our interventions at the pilot scale can later be integrated into further local community development, and (ii) additional sites for similar pilot experimentation with local citizens can be accommodated into the project scheme.

Extension is represented by the Department of Agriculture of Bangka Regency (Dinas Pertanian Kabupaten Bangka), an institution of the municipality that works in collaboration with the Ministry of Agriculture (Kementerian Pertanian). The six involved smallholder farmers belong to a local group of twenty pioneer farmers who have worked in close collaboration with local extension services for the past years in order to improve agricultural productivity, especially on degraded ex-mining lands. These farmers are subsistence farmers and habitually complement agricultural activities with fishing. Since the farmers live and work in two neighboring villages, the administrative heads of both these villages are involved and support the joint field experiments of the present study. The region harbors a rather newly established research institute (Badan Pengkajian Teknologi Pertanian Kepulauan Bangka Belitung (BPTP), Indonesian Agency for Agricultural Research and Development of Bangka Belitung Island, Ministry of Agriculture, in English) of the Ministry of Agriculture. The research institute's task is to perform very applied research into locally adapted crop diversification, value chain development, 
and nutrient management options and to deliver these results to farmers in the province with the support of local extension. Various researchers of this institution have repeatedly been involved in project steps (consultation on crops to be cultivated, consultation on and assistance with available soil amendments, feedback rounds on project progress and outlook, natural and man-made reclamation activities in the region, etc.). In the Indonesian system, agencies like BPTP perform applied research to address community challenges and governmental development plans. Implementation (or knowledge transfer) is assured through extension services. These agents are university-trained practitioners for whom communication with communities is key. The academic partners are the Universitas Gadjah Mada (UGM) based in Yogyakarta, Indonesia, and the University for Natural Resources and Life Sciences Vienna (BOKU), Austria. These partners contribute scientific methodology to the project. In addition, laboratory data of soil analyses can be used to explain observations, for example when discussing with core partners at the field site.

\subsection{Experimental Field Site}

The core partners jointly set up an experimental field site in close proximity to the fields of the involved smallholder farmers in the summer of 2018. This site is located on formerly mined land, that could still be used to mine tin (see Figure S1). However, before the experimental field site was set up, the farmers had already decided to switch from mining the area to using it for agriculture. There is also government backing for these plans, since the entire area belongs to one of the areas targeted for preferential re-habilitation by governmental development plans. Farmers' buy-in is crucial, since land that has already been given up by large-scale exploiters is frequently being re-mined by small-scale operators, even after re-habilitation activities have been undertaken. Sadly, this is to be expected if not enough profit can be made off freshly re-habilitated land to be able to refrain from tin exploitation, further strengthening the need to directly include affected stakeholders in the development of soil re-habilitation strategies. However, seeing tin reserves and profits from mining declining, the farmers involved in the present work view agriculture as a more viable livelihood option: "I am happy with my job [as a farmer, explanation added], because I believe that my children can continue this work. Mining has no future for my family" [34]. The agricultural community is growing in the area of the study site [35] as more people become interested in farming as a livelihood strategy. This illustrates the necessity to restore degraded lands, especially since increasing production with the existing agricultural areas alone is hard to accomplish [5].

To establish the experimental field site, the area had to be levelled and 24 plots of $2 \times 2 \mathrm{~m}$ in size were established. Several soil amendments were tested with four replicates for each amendment. The amendments used were lime, compost, charcoal, a combination of charcoal and compost, as well as a combination of charcoal and sawdust. Similarly, an array of four plots was left untreated as a control. Concentrations of single treatments were $10 \mathrm{t} / \mathrm{ha}$, and of mixed treatments-20 $\mathrm{t} / \mathrm{ha}$ in total (10 $\mathrm{t} / \mathrm{ha}$ per amendment). Lime is routinely being used by farmers as a soil additive on Bangka Island and was procured from a local input seller; compost was produced at the local research station; sawdust and charcoal were purchased at a local sawmill. Directly upon preparation of the experimental site, a combination of Centrosema pubescens and cassava (Manihot esculenta Crantz) was planted.

In case of this co-experimentation project at the pilot scale, different funds could be mobilized to obtain soil amendments: funds from UGM were employed to purchase lime, sawdust, and charcoal; seeds were provided as material support by the mining company PT Timah; the local research station contributed compost for free. For farmers wishing to invest in their agricultural activities but lacking capital, an option is to apply as a group for material (very common) or financial (rather uncommon) support from governmental and private actors, e.g., mining companies. Farmer groups must fulfil certain criteria (minimum 20 members, organizational structure including head and secretary, regular activities) and be formally registered with the government. While these processes appear very formal and hierarchical, it is a doable way for farmer groups to secure at least some support for their activities. This practice is common on Bangka island. 


\subsection{Shared and Specialized Activities within the Co-created Project}

The experimental field site is at the core of this project (see Figure S4). It validates approaches that have been described in controlled laboratory and pot experiments in a field situation under natural conditions. Furthermore, it also provides an opportunity for co-experimentation of involved farmers and researchers. Most of the activities that are connected to the field site, such as preparation of the experimental site, harvesting and yield determination, sampling soil and plants, can be and are performed jointly (see Table 1).

Table 1. Overview of Shared and Specialized Activities Related to Co-Experimentation at the Field Site. Participation in an activity is marked in the column of the respective research partner (farmers or researchers) with an $x$.

\begin{tabular}{ccc}
\hline Activity & Farmers & Researchers \\
\hline (1) Setting agenda for research process (idea, & $\mathrm{x}$ & $\mathrm{x}$ \\
questions, implementation) & $\mathrm{x}$ & $\mathrm{x}$ \\
(2) Physical work at experimentation site & $\mathrm{x}$ & $\mathrm{x}$ \\
(3) Discussion about crops to cultivate & $\mathrm{x}$ & \\
(4) Managing field site all year-round & Year-round & At visits only \\
(5) Observations at field site (water management, & $\mathrm{x}$ & $\mathrm{x}$ \\
soil, plant growth, pest load, etc.) & $\mathrm{x}$ & $\mathrm{x}$ \\
(6) Harvesting and yield determination & & $\mathrm{x}$ \\
(7) Sampling (soil, plant biodiversity, crops) & $\mathrm{x}$ & $\mathrm{x}$ \\
(8) Laboratory analysis & & \\
(9) Evaluation of results at experimentation site &
\end{tabular}

However, there are few specialized activities that cannot be performed by all of the partners: close observation and certain management decisions (e.g., irrigation management) cannot be accomplished by researchers working most of the year outside of the study area; for these inputs, the project relies on the expertise of the involved local farmers; laboratory analyses of soil and plant samples, on the other hand, can only be performed by formally trained scientific staff with access to the respective infrastructure. We consider it important to stress that researchers and farmers jointly discussed the project steps, mostly in consultation with other stakeholders: for example, in case of choosing crops to cultivate and soil amendments to test, farmers and scientists discussed possible options, informed by additional consultation of extension and colleagues from the local research station.

\subsection{Interviews, Participant Observation and Field Notes}

Semi-structured interviews were conducted with core partners at the time of installation of the experimental field site, as well as at the first harvest in the following year. These were transcribed and translated by the Indonesian research team members to English. All researchers were involved in analyzing and discussing findings from these data. Workshops for feedback and outreach, and installation of the field site served as occasions for participant observation. Informal interactions during project co-creation or implementation steps were used to create field notes. Field notes and transcribed interviews served to triangulate findings from participant observation. Besides core partners, partners from the intermediate and outer layers were also interviewed.

\subsection{Timeline of Activities}

Many actions that led to the development of the present study took place long (up to two years) before the first project activities were implemented in the field site (see Figure 3). 


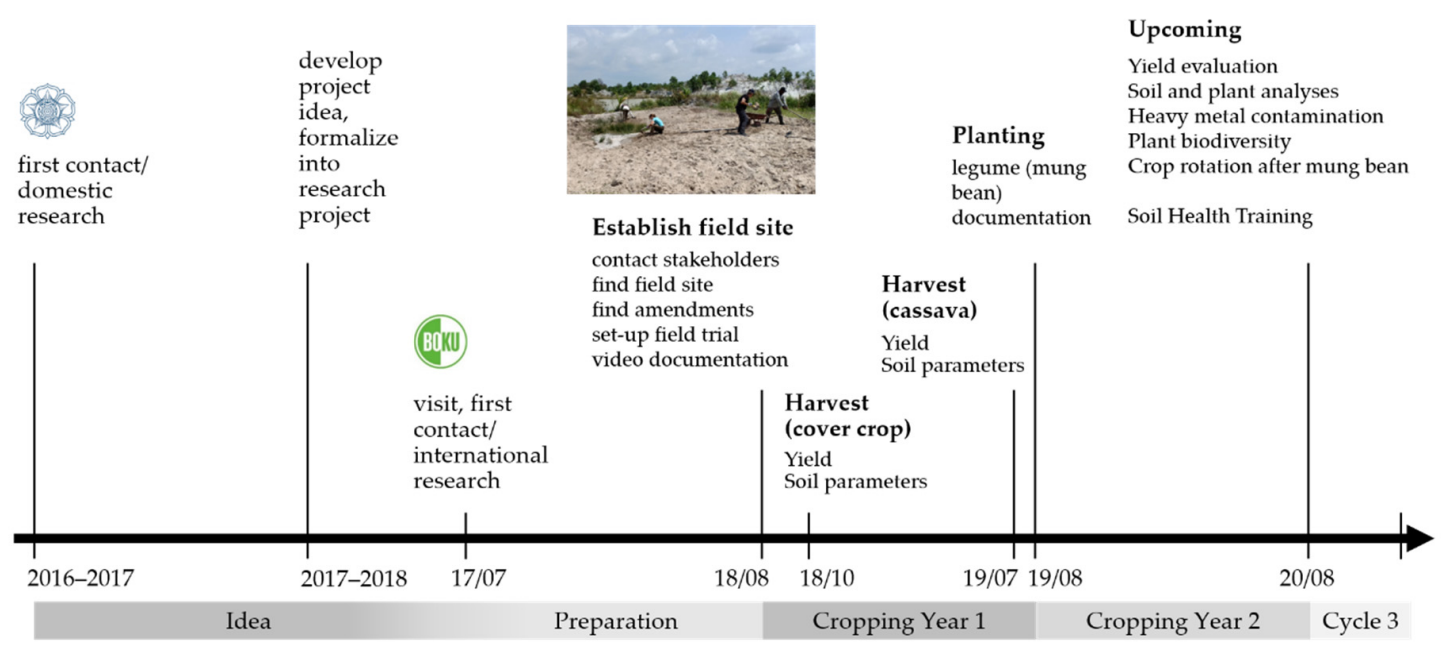

Figure 3. Timeline of activities. The actual project start can be dated to the installation of a field experimentation site in August 2018 (18/08), although preparatory activities started around two years before that. Dates are given as years (four-digit) or as years/months (two-digit/two-digit).

The project idea that led to the present study developed from these first contacts between local farmers, extension and domestic research institutions. These interactions date back to 2016/2017, well ahead of the establishment of the experimental site. In the summer of 2017, a first exploratory visit of domestic and Austrian researchers served to identify possible common interests for collaboration. During the following year, the project idea was formalized and preparatory actions were taken (consultation of local stakeholders, domestic and international researchers on a remote basis). It soon became clear that an experimental plot was needed to test several amendments, to test their ability to improve soil structure and function. In addition, this field site was intended as a hub for co-experimentation of farmers and scientists. Several possible locations were identified, and possible amendments were discussed. The best option proved to be setting up the experimental plots in close proximity to the involved farmer group, since experimental conditions at the field site had to (i) reflect the conditions that the farmers face in their own fields as far as possible, and (ii) be freely accessible to the farmers and interested public at all times. Not only would the involved farmers thus be able to monitor crop growth closely, they would also be able to benefit directly from the harvest.

\subsection{Outreach Strategy}

As an outreach strategy, we implemented several measures. The most straightforward and less time consuming, but also less interactive, measure was a descriptive, weatherproof poster on display in the experimental field site. In addition to this local, physical option, we decided to provide video documentation of the project context, set-up and progress (see Figure S2). This accompanying video documentation can be employed for teaching at university, training in extension, and outreach to a more general public. The first video describes local challenges for agriculture and documents, how farmers and researchers jointly establish the experimental field site. It is available in English (https://youtu.be/3nH356Ldxxk), as well as in Bahasa Indonesia (https://youtu.be/HbYOvgf_ywk). A second video is currently in preparation. This upcoming documentation will cover the harvest after the first year of cultivation, sampling of soils and plants at the field site, and strategies for further improvement of soils and crop production in the second year of experimentation.

Co-experimentation allowed for more direct exchange between farmers and researchers. First, the field site provided a more informal setting; second, the physical work performed jointly in the field site supported dynamic leadership and facilitated building meaningful working relationships (see Sections 5.1 and 5.2.1). At each field visit, we therefore chose to film most of the interviews for the accompanying documentation on-site and after joint work in the field had been finished. 


\subsection{Scaling-Up Strategy}

In the presented work, the core partners' task is to co-develop locally adapted options to improve the natural resource base and to render NRM more sustainable. The co-experimentation approach we describe here is designed at a pilot scale and is best implemented in a small-to-medium group that allows for regular personal interaction among core partners (farmers and researchers). Partners in the intermediate (e.g., extension services, research station) and outer layers (government, mining company) are better placed to scale up successful options. Not only can these partners rely on their expertise in scaling-up innovations or new farming techniques, they also have access to the respective interaction partners or certain resources needed to do so.

Scaling-up at district level is at the hands of local extension services, while moving to other districts in the province of Bangka-Belitung can be facilitated through the local research station. The institute works in close cooperation with the Ministry of Agriculture, operates on locations on both islands of the province and has access to sites for experimentation. Extension services, on the other hand, assure knowledge sharing between research and farmers, for example on new farming strategies or innovations, and raise awareness of environmental concerns.

In the present work, we focus on the natural resource base and the production side of agriculture as a livelihood option since this fits the expertise of the involved researchers. However, it should be stressed that activities targeting other aspects (e.g., reduction of post-harvest losses, development of value chains and marketing approaches) are being undertaken by complementary governmental actors in Bangka-Belitung. Several of these actors (e.g., head of regency, head of development agency, etc.) are involved in exchange on the co-experimentation approach, albeit at a lesser frequency than the partners of co-experimentation.

\section{Results}

\subsection{Development of the Research Partnership}

We want to stress that this project was not planned in a traditional academic way, where brainstorming on the side of researchers, grant writing, and application for funds in most cases precede contact with local stakeholders (using the language of participatory approaches) or recruitment of volunteers (using terms more common in CS) [36]. Instead, this study organically developed from a challenge that local farmers and extension are facing and that they felt warranted pulling in additional expertise to complement their own efforts and activities. The "recruitment process" was thus reversed: while smallholder farmers and extension had an overarching research topic in mind, it was the scientists who were pulled in in a stepwise process, starting with domestic research.

The Department of Agriculture Bangka Regency, the local equivalent of extension, was instrumental in kick-starting the process that led up to the inception of the project. It was this institution which linked up two types of stakeholders with whom it was already collaborating in different ways: the local farmers and national research and higher education, namely UGM. Through a long-standing collaboration between UGM and BOKU, the present set of academic partners was recruited to the not yet established project.

\subsection{Decision-Making Criteria for Implementation of the Field Site}

Several interests had to be taken into account when setting up the field site. Partners had different preferences for soil amendments or crops they favored. In case of competing interests, preference was given as far as possible to farmers' perspectives. As the perspectives of all involved core partners, and as far as possible also of the partners in the intermediate layer, should be incorporated into final decisions on soil amendments and cultivated crops, it was necessary to align interests from different stakeholders (see Figure 4). 


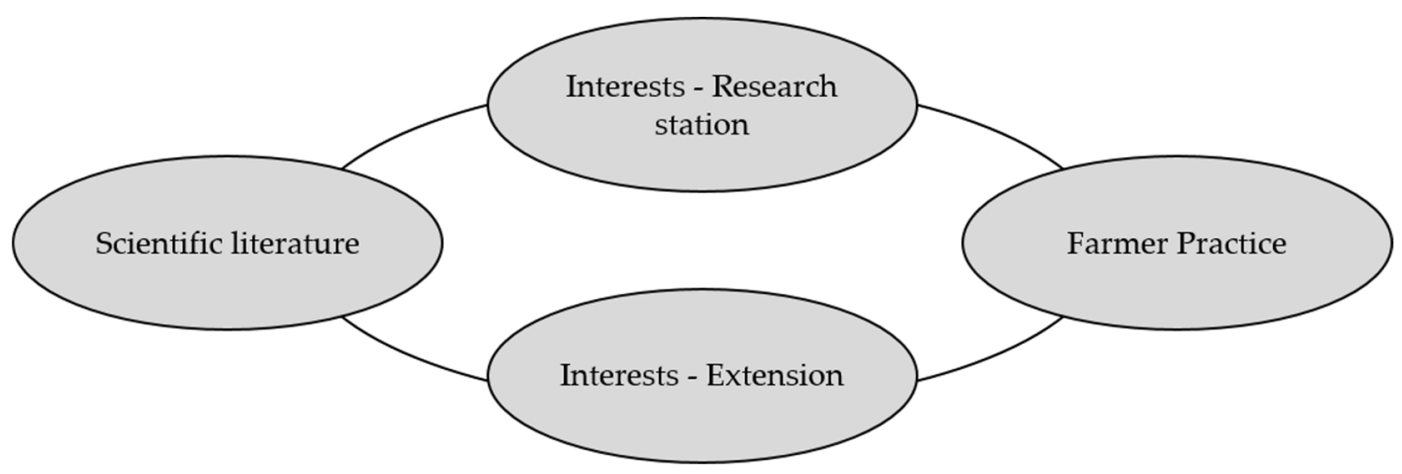

Figure 4. Schematic representation of perspectives and interests that had to be aligned for decision making on soil amendments and crops to be cultivated at the experimental field site.

An overview of the criteria that were used to determine which soil amendments were to be used and which crops were to be cultivated in the experimental field site is given in Table 2 .

Table 2. Criteria for Decision Making. Left: List of criteria that were used to decide on soil amendments. Right: Overview of criteria that were used to decide on crops to be cultivated. Time-efficient cultivation means low labor requirements.

\begin{tabular}{cc}
\hline Soil Amendments & Crops to Cultivate \\
\hline Potentially beneficial for soil properties & Value: economic or personal use \\
Potentially beneficial for yields & Edible for humans and/or fodder for livestock \\
Locally available & Tolerant to low nutrient availability \\
Affordable for local farmers & Locally accepted \\
Possibly already in use & Rotation after year 1 \\
Homogeneous application possible & Tolerant against pests \\
& Time-efficient cultivation \\
& Seasonally adequate \\
\hline
\end{tabular}

Following Becker's conceptual framework for assessing sustainability [37], we took ecological, economic, and social aspects into consideration (see Table 2); among the criteria for soil amendments and cultivated crops, we aimed to integrate ecological benefits, economically viable options, socially feasible (e.g., in terms of workload or possible previous experience) and accepted (e.g., in terms of cultural preferences for certain foods). The cover crop Centrosema pubescens was chosen because it is a nitrogen-fixing legume that is commonly used on the island and grows fast. Thus, it can provide protection against erosion by wind and water. Further, farmers can use it as fodder for their cows once yield has been determined. Cassava was used as the main crop because it is a common and popular staple crop in Bangka, and because it is also able to tolerate harsh environments that supply few nutrients as is the case in ex-mining lands.

\subsection{Management and Yields at the Experimental Field Site}

Cassava yields were increased by all treatments and ranged between 3.94-5.44 t/ha, compared to the control where only $2.5 \mathrm{t} /$ ha cassava could be harvested (below-ground biomass only [2,38]). These results are encouraging, especially since with single measures (soil amendment with one-time application) we were already able to increase yields 1.5 -fold to more than twofold compared to the untreated control. Farmers were satisfied with the yield obtained at the experimental field site $[39,40]$.

\subsection{Feedback from Involved Farmers, Extension, and Local Research Station}

The visions of government and administration seem well-aligned with the motivations that local farmers mention for prioritizing farming over mining: "We tend to agriculture [as a source of income, 
explanation added]. Agriculture provides for income. In Bangka, the income from other jobs is decreasing. So, we shifted to agriculture" [39].

Farmers often voiced concerns about low productivity in degraded areas and placed improvement of soils at the center of their attention. One of the farmers of the core partner group summarized his experiences after the first year of co-experimentation as follows: "It is useful for people or farmers to understand about soil nutrients. We gradually improve our knowledge about the nutrients needed in the soil to cultivate every crop" [39]. The present study was able to provide directions for re-habilitation of formerly mined land.

The location of the experimental field site proved a good choice. Even a farmer who was not directly involved in co-experimentation, but whose fields neighbor the site, followed what was happening on the adjacent land and concluded: "The interesting point is that unfertile land has been improved to land where we can grow crops" [41].

Partners from the local research station are already thinking about scaling out the experimental approach. Currently a branch of the institute is being established on the neighboring island of Belitung, which also suffers from severe land degradation after tin mining activities. The present approach could thus soon be replicated on the second island of the province.

\section{Discussion}

\subsection{Leadership}

The present study could be described as a large co-consultation process with field experimentation. Leadership lies to a large extent with the group of core partners, involving also some partners of the intermediate layer. However, among those partners, the leading is dynamic and changes at different stages. This might appear messy from an outside perspective, but it reflects the organic development of the research partnership. In addition, more flexible leadership enables the project to react quickly to changing needs, new developments, or should unforeseen challenges appear (e.g., delayed rainfall, Covid-19 pandemic).

The occasion of levelling the field site illustrates the feeling of ownership and degree of engagement of the involved smallholder farmers and can be used to demonstrate what we mean by fluid leadership. As a first measure, farmers and researchers had to manually level a deep pit in the middle of the former mining area. However, once the deepest pits had been filled, farmers realized that the progress being made was too slow, and that the ground was now "even" enough to complement the manual work with machine work. To speed up the process, they organized the tractor from the local cooperative and levelling was completed using machine labor.

\subsection{Success Factors}

\subsubsection{Building Meaningful and Trustful Working Relationships}

In our description of the present project, we put emphasis on the long-standing relationships that led up to the inception of the project and were crucial for the study's success in involving citizens in the scientific process. Many partners knew each other before and had previously worked together in different contexts. This solid basis was complemented by the preparedness to involve new partners as necessary or beneficial for the project. This is not just a convenient interpretation of the researchers involved in the study. At the beginning of experimental field work in 2018, one of the farmers put it quite directly: while chatting with those of us who had visited the later study site in 2017, he mentioned how many people come to Bangka island to talk to locals about challenges, especially related to mining activities, take pictures or shoot videos, interview locals, but then leave and never return. He emphasized how this interaction was different, since not only did the researchers return the following year, they also brought some more colleagues with them. This was taken as a sign of 
commitment on our, the researchers', side and work on the experimental site was started in a very partner-like, engaged way.

Mutual esteem between farmers and scientists has developed-each can learn from any other member, as is frequently hoped for under such conditions [36]. The research station's staff provide valuable expertise on re-cultivation and climate change adaptation; farmers had already started to re-cultivate by themselves and have a "sense" of the soil; and so forth. As scientists, we are sometimes regarded as "those who do not work [physically]" [42]. Sometimes, we might even feel being put to the test in the field before we can be trusted (A.M.) Here, the formation of a group identity of all core partners was certainly aided by sharing the physical work in the field site-and maybe by doing this, to defy stereotypes of "the people from university who come to visit [meaning to look at things, but not to participate in physical work, explanation added]". The term "co-creation" even develops a very physical connotation. Having finished to sow the seeds in 23 out of 24 plots, one of our team members was addressed approvingly by one of the farmers as "a strong woman"; on another occasion, a team member remembers having been compared in strength to a soldier for working with very few breaks in the hot and humid climate.

\subsubsection{Continuity and Flexibility}

Related to the above, the described co-experimentation approach relies on continuity. It is impossible to develop combinations of soil amendments and cropping patterns which can sustainably improve soils and agricultural productivity in just one or two seasons. Yet this is frequently attempted, leading to disappointment at wanting results that translate poorly to farmers' life realities. One of the strengths of this approach is that it is set up for several years, with continued exchange between researchers and farmers. Co-experimentation necessitates adaptation (see Section 5.3), and willingness to pull in additional (new) partners when needed (see Section 2.2, Section 3.2, Section 3.8, and Section 6.2). Not in all cases will it be possible to anticipate which partners will have to be pulled in at later stages; some flexibility is therefore needed.

\subsubsection{Assuring Functional, Bi-Directional Communication}

Here, the responsibility of verbal communication lies almost exclusively in the hands of the Indonesian team members. However, fast, bidirectional communication, even across large spatial distances, is key.

\subsubsection{Low Cost of Participation for Farmers}

Often, citizens wishing to participate in the scientific process have to learn specialized methods, follow certain protocols, or familiarize themselves with new technologies (e.g., smartphone-based apps, etc.) for recording phenomena, species, or for submitting data. Researchers are frequently worried about assuring a high quality supplied by volunteers who still need to train themselves in the techniques required to take part in a CS project [43]. This is even more important for large-scale approaches wishing to assure common standards across a diverse group of contributors. The present study differed from other projects described in the literature, as farmers did not have to use new technologies, equipment, or procedures to be able to participate in the co-experimentation process. Our co-experimentation approach relies on skills that farmers already have at their disposal and that they routinely use in their farming operations. This point warrants special attention, since it saves farmers' limited time and eliminates concerns on the quality of established data. Farmers are autonomous from scientists (based for most of the year abroad) in their assessment of yields from different experimental plots. Similarly, improvements in soil structure (easier plant rooting) and water retention capacity (moisture content) are readily accessible to farmers. Such results were of course discussed at field visits and triangulated using laboratory data. Still, farmers' independence in assessing experimental outcomes is central to the described co-experimentation approach. 
Relying on a set of existing skills and daily practices allowed low-threshold participation of partners who do not belong to (more readily recruited) specifically science-prone groups and are notoriously difficult to target in participatory approaches (multiple jobs, few own resources, considerable time constraints).

\subsubsection{Logistics}

The value of reliable functioning of logistics is often overlooked, but it cannot be overestimated.

\subsection{Aligning Conflicting Preferences}

In such a diverse group of partners, there are bound to be different perspectives and preferences. Still, a common way forward has to be found through discursive settlement. Two such examples shall be given here. While the first addresses different interests in the choice of soil amendments, the second illustrates diverging priorities in choice of crops to be cultivated. Zeolites, alumosilicates of volcanic origin, are known in scientific literature for their high cation exchange capacity that can reduce nitrogen leaching and improve nutrient availability and soil structure [44]; further, their porosity is beneficial for water storage and they can help to adsorb toxic metals [45]. Therefore, academic research would have been very interested in testing zeolites in the experimental field site. However, even though such alumosilicate deposits are present on the island, the option had to be abandoned: even if zeolites could have been purchased for the pilot experiment, local smallholders would never be able to afford the product, precluding scaling-out of the intervention should it prove beneficial. Similarly, the research institute would have preferred to cultivate other crops than cassava in the first year, since they already invested into studying these crops and investigating their potential to increase agricultural productivity on Bangka island.

\subsection{Motivation}

Some participants become involved in CS projects to contribute to science, others to improve their living conditions [46,47]; in both cases, it can be equally important to gain new experiences, which can be rewarding in itself [47]. The approach of co-experimentation appears to have held some reward for spent time and energy for the involved farmers; how else could we explain the conclusion of one of the farmers involved in co-experimentation from the beginning at the time of the first cassava harvest: "The plot is good, [I] like it, in my opinion, ... I like everything about the plot" [48]. Farmer partners are no novices to experimentation $[40,49,50]$, still they could have well enjoyed the systematic approach that they experienced in co-experimentation. Surely, the interest in the scientific method was high, as frequent questions on motivation and experimental justifications in the field corroborate.

\section{Outlook}

\subsection{Co-Experimentation at Field Site}

The first year has brought remarkable successes for several of the test plots insofar as we were able to increase cassava yields to at least 1.5-fold of the yields from control plots. In some cases, we could even double the yields compared to control plots, with a single application of soil amendment(s) only. The harvest of the second year is due soon. However, with the world-wide pandemic (as of 2020), prospects to travel remain grim. At time of writing, travel restrictions make field visits highly unlikely for the international team members, including one of the Indonesian team members currently based in Austria. For the domestic-based team members, the situation is not clear yet. Remote consultation with core team members abroad is available through the vital communication network that the Indonesian team members assure. Still, most likely our local core partners will harvest and determine yield but will also have to implement some management adaptations for the upcoming third year of experimentation, entirely on their own. Past experiences allow for optimism: since ownership of the experimental field site among local partners is high, technical steps like yield determination are unlikely to pose 
challenges. More adaptation will be needed to ensure smooth communication among the different stakeholders to discuss management options for the upcoming year, as well as to decide jointly on steps to take. There has always been continued communication on a remote basis, but previously we invested considerably in face-to-face communication and joint physical work in the field. Travel restrictions now severely hamper this key pillar of our approach.

The domestic research and higher education partner UGM is present across all of Indonesia with community service projects. Participation is mandatory for all students, irrespective of the chosen subject, and involves a medium-length, several-weeks-long field stay. Likewise, supervision of community service projects is mandatory for UGM researchers once per year. These interdisciplinary, applied projects focus on specific challenges of local communities. One of the aims of the program is to sensitize students to the challenges Indonesians face in the highly diverse rural areas of the country, and to provide a learning environment that is inspired by practice and can thus complement purely academic training. In addition to the inclusion of a second experimental site brought forth by the local research station, we would also like to complement this pilot study with such a community service project.

In addition, we have recently been successful in winning a grant from the Indonesian government to support a PhD student, which further strengthened also international collaboration.

\subsection{Scaling-out of Successful Options for Improving the Natural Resource Base and Rendering NRM more Sustainable}

First measures for scaling-up have already started: at the harvest in summer 2019, core and intermediate partners presented the co-experimentation approach and first results to extension agents and other interested farmers (see Figure S3). This event was particularly unusual and symbolic, since it brought together farmers and extension agents for joint discussion. These two groups of stakeholders normally do not train together; that joint discussion was possible in this context further underscores the partnership-like approach we advocate. At the same time, it emphasizes the central role of innovative pioneer personalities in this process: again, the head of the local extension service, who had already been instrumental in bringing together researchers and farmers, facilitated the discussion between farmers and extension agents.

Partners from the local research station who focus on the production side have begun to promote activities among colleagues focusing on the economic and post-harvest side. Options for extending the co-experimentation approach to the neighboring island of Belitung are already being explored. Further activities for integration of the present work with other, complementary activities that are already scheduled or being implemented in the networks of the partners, are envisaged.

\section{Conclusions}

Based on our experience in the present study, we see a possible contribution of CS to the SDGs in two areas: involving stakeholders in the scientific process can improve the practical relevance of scientific findings, but it can also contribute to procedural outcomes through fostering meaningful, respectful, and trusting working relationships between academic and non-academic partners. Trying to accommodate perspectives and priorities of different stakeholders is never straightforward and necessitates constant, bi-directional communication and balancing of divergent interests, but it is worth the effort.

Co-experimentation on a pilot scale can be useful for developing locally adapted interventions. An advantage of the presented approach is that farmers did not have to acquire new skills to be able to participate in the scientific process of knowledge generation, allowing for some autonomy in evaluating tested options.

The success of the present study is based on the relationships that were formed. This is due to the time that was invested from the sides of all involved partners, but also to the jointly performed physical work in the experimentation site that helped to create a team spirit among partners. 
Supplementary Materials: The following are available online at http://www.mdpi.com/2071-1050/12/18/7700/s1, Figure S1: Joint Establishment of Co-Experimentation Site, Figure S2: Production of Outreach Material at Field Site, Figure S3: Example of a Scaling-Out Activity of a Partner, Figure S4: Group Picture with Partners after Harvesting, Sampling, and Preparing for Second Year of Cropping.

Author Contributions: All authors designed the study. Likewise, all authors contributed to organizational and administrative issues, albeit often in different geographic locations. Conceptualization, methodology, investigation, and formal analysis, R.M.K.; R.M.; A.M.; M.M.; N.N.; K.M.K. All authors contributed resources; in addition, A.M. contributed camera and audio equipment; R.M.K. drafted the manuscript and figures and edited after review, all authors critically reviewed the manuscript; supervision, K.M.K. and N.N.; funding acquisition, R.M.K.; R.M.; A.M.; M.M.; N.N.; K.M.K. All authors have read and agreed to the published version of the manuscript.

Funding: This research was funded by ASEA-Uninet, grant numbers 2019/BOKU/2 and 2018/BOKU/4, the Austrian Development Agency, grant number 2706-00/2018, Erasmus+ actions (R.M.K. and R.M. 2018/2019), and by the Indonesia-Austria Scholarship Program in collaboration between the Ministry of Education and Culture of Indonesia and OeAD GmbH, grant number 75/D3/PG/2019. The APC were funded by the BOKU Vienna Open Access Publishing Fund. The funders had no role in the design of the study; in the collection, analyses, or interpretation of data; in the writing of the manuscript, or in the decision to publish the results.

Acknowledgments: We would like to thank the farmers who are involved as our partners in this study. Without them, none of these CS activities would have taken place. We would also like to thank Pak Kemas Arfani Rahman (Head of Agriculture Department of Bangka Regency) for his role in the inception and for his continuing support as an ambassador of our joint project. We would like to acknowledge Mulkan, SH., MH., governor of Bangka Regency, and both village heads of the two villages adjacent to the field site. Special thanks go to Pak Dedi (Mega Tour and Travel), not just for being a most reliable driver, but also for supporting us in many other ways, including establishing contacts, lending a hand in the field at harvest times, and, last but not least, for welcoming the PhD student in the team on her numerous field visits to his family. We would further like to thank BPTP Bangka Belitung not just for spending time to discuss, but also for compost from their research station. We thank PT Timah for Centrosema pubescens seeds. Special thanks go to Michael Gartner, Lebensmittelversuchsanstalt LVA $\mathrm{GmbH}$, who, being as enthusiastic about research and analytical chemistry as he is, supports us with sample processing. We are grateful to Rebecca Hood-Nowotny for her support in $\mathrm{C} / \mathrm{N}$ isotope analyses and from now on also in co-supervision of the involved PhD student; further, we would like to thank her for providing valuable comments on the manuscript and for English language editing. We would also like to acknowledge Sebastian Postl, BOKU Media Services, who readily shared his technical know-how on filming, on one occasion even his private camera, and who was instrumental in assembling the available video documentation. R.M.K. would like to thank Marie-Luise Matthys for passionately discussing participatory approaches and video. Finally, we would like to thank two anonymous reviewers for their stimulating feedback on a prior version of the manuscript.

Conflicts of Interest: The authors declare no conflict of interest.

\section{References}

1. U.S. Geological Survey. Mineral Commodity Summaries 2020; U.S. Government Publishing Services: Washington, DC, USA, 2020.

2. Maftukhah, R.; Ngadisih, N.; Murtiningrum, M.; Mentler, A.; Keiblinger, K.; Kral, R.; Gartner, M. Soil amendments to re-establish agricultural production on ex-tin mined area. In Proceedings of the EGU 2020, Vienna, Austria, Online. 4-8 May 2020.

3. Sari, S.P.; Rosalina, D. Mapping and Monitoring of Mangrove Density Changes on tin Mining Area. Procedia Environ. Sci. 2016, 33, 436-442. [CrossRef]

4. Aspinall, C. Small-Scale Mining in Indonesia; MMSD, IIED: London, UK, 2001; No. 79.

5. Kemas, A.R. Interview with Pak Kemas, Head of Department of Agriculture, Bangka Regency (Dinas Pertanian Kabupaten Bangka). Interview conducted on 29 July 2019, Interview by Murtiningrum, M., Kral, R.M., Keiblinger, K.M., written translation by Murtiningrum, M. Unpublished Work.

6. Mulkan. Interview with Mulkan, Governor of Bangka Regency (Bupati Kabupaten Bangka). Interview conducted on 2 August 2019, Interview by Ngadisih, N., Kral, R.M., written translation by Murtiningrum, M. Unpublished Work.

7. Blum, W.E.H. Functions of Soil for Society and the Environment. Rev. Environ. Sci. Biotechnol. 2005, 4, 75-79. [CrossRef]

8. Keesstra, S.D.; Bouma, J.; Wallinga, J.; Tittonell, P.; Smith, P.; Cerdà, A.; Montanarella, L.; Quinton, J.N.; Pachepsky, Y.; Van der putten, W.H.; et al. The significance of soils and soil science towards realization of the United Nations Sustainable Development Goals. Soil 2016, 2, 111-128. [CrossRef] 
9. Dominati, E.; Mackay, A.; Green, S.; Patterson, M. A soil change-based methodology for the quantification and valuation of ecosystem services from agro-ecosystems: A case study of pastoral agriculture in New Zealand. Ecol. Econ. 2014, 100, 119-129. [CrossRef]

10. Haines-Young, R.; Potschin, M. Common International Classification of Ecosystem Services (CICES) V5.1 and Guidance on the Application of the Revised Structure. Available online: www.cices.eu2018 (accessed on 29 July 2020).

11. ESDM. Regulation of the Minister of Energy and Mineral Resources of the R.I. Number 07 Year 2014 Concerning Reclamation and Postmining in Mineral and Coal Mining Business Undertaking; ESDM: Jakarta, Indonesia, 2014.

12. UN General Assembly. Transforming Our World: The 2030 Agenda for Sustainable Development; UN: New York, NY, USA, 2015.

13. Lawrence, A. The first cuckoo in winter: Phenology, recording, credibility and meaning in Britain. Glob. Environ. Chang. 2009, 19, 173-179. [CrossRef]

14. Eitzel, M.; Cappadonna, J.; Santos-Lang, C.; Duerr, R.; West, S.E.; Virapongse, A.; Kyba, C.; Bowser, A.; Cooper, C.; Sforzi, A.; et al. Citizen Science Terminology Matters: Exploring Key Terms. Citiz. Sci. Theory Pract. 2017, 2, 1-20, ISSN 2057-4991. [CrossRef]

15. Purkart, A.; Depa, Ł.; Kollár, J.; Suvák, M.; Holecová, M.; Goffová, K.; Országhová, Z. Citizen science reveals the current distribution of the new plant pest Aphis nerii in Slovakia. Plant Prot. Sci. 2020, 56, 101-106. [CrossRef]

16. Ryan, S.F.; Lombaert, E.; Espeset, A.; Vila, R.; Talavera, G.; Dincă, V.; Doellman, M.M.; Renshaw, M.A.; Eng, M.W.; Hornett, E.A.; et al. Global invasion history of the agricultural pest butterfly Pieris rapae revealed with genomics and citizen science. Proc. Natl. Acad. Sci. USA 2019, 116, 20015-20024. [CrossRef]

17. Hiller, T.; Haelewaters, D. A case of silent invasion: Citizen science confirms the presence of Harmonia axyridis (Coleoptera, Coccinellidae) in Central America. PLoS ONE 2019, 14, e0220082. [CrossRef]

18. Ryan, S.F.; Adamson, N.L.; Aktipis, A.; Andersen, L.K.; Austin, R.; Barnes, L.; Beasley, M.R.; Bedell, K.D.; Briggs, S.; Chapman, B.; et al. The role of citizen science in addressing grand challenges in food and agriculture research. Proc. R. Soc. B Biol. Sci. 2018, 285, 20181977. [CrossRef]

19. West, S.; Pateman, R. How Could Citizen Science Support the Sustainable Development Goals? Policy Brief; Stockholm Environment Institute: Stockholm, Sweden, 2017.

20. Senabre, E.; Ferran-Ferrer, N.; Perelló, J. Participatory design of citizen science experiments. Comunicar 2018, 26, 29-38. [CrossRef]

21. Lawrence, A. "No Personal Motive?" Volunteers, Biodiversity, and the False Dichotomies of Participation. Ethics Place Environ. 2006, 9, 279-298. [CrossRef]

22. Serrano Sanz, F.; Holocher-Ertl, T.; Kieslinger, B.; Sanz Garcia, F.; Silva, C.G. White Paper on Citizen Science in Europe; Societinize Consortium: Zaragoza, Spain; Coimbra, Portugal, 2014.

23. Ceccaroni, L. Civic education and citizen science: Definitions, categories, knowledge representation. In Analyzing the Role of Citizen Science in Modern Research; Ceccaroni, L., Piera, J., Eds.; IGI Global: Hershey, PA, USA, 2016; p. 320. ISBN 978-1-5225-0962-2.

24. Chambers, R.; Pacey, A.; Thrupp, L.A. Farmer First: Farmer Innovation and Agricultural Research, Reprint; Intermediate Technology Publ: London, UK, 1998; ISBN 9781853390074.

25. Pretty, J.N. Participatory learning for sustainable agriculture. World Dev. 1995, 23, 1247-1263. [CrossRef]

26. Hoffmann, V.; Probst, K.; Christinck, A. Farmers and researchers: How can collaborative advantages be created in participatory research and technology development? Agric. Human Values 2007, 24, 355-368. [CrossRef]

27. Shiferaw, B.A.; Okello, J.; Reddy, R.V. Adoption and adaptation of natural resource management innovations in smallholder agriculture: Reflections on key lessons and best practices. Environ. Dev. Sustain. 2007, 11, 601-619. [CrossRef]

28. Irwin, A. Citizen Science: A Study of People, Expertise and Sustainable Development; Routledge: London, UK, 1995; ISBN 0-415-13010-7.

29. Cooper, K.B.; Lewenstein, B.V. The two meanings of citizen science. In The Rightful Place of Science: Citizen Science; Cavalier, D., Kennedy, E.B., Eds.; Consortium for Science, Policy, and Outcomes: Tempe, AZ, USA, 2016.

30. Silvertown, J. A new dawn for citizen science. Trends Ecol. Evol. 2009, 24, 467-471. [CrossRef]

31. Chambers, R. Knowing in Development: A Radical Agenda for the Twenty-First Century. Forum Dev. Stud. 2014, 41, 525-537. [CrossRef] 
32. Fritz, S.; See, L.; Carlson, T.; Haklay, M.; Oliver, J.L.; Fraisl, D.; Mondardini, R.; Brocklehurst, M.; Shanley, L.A.; Schade, S.; et al. Citizen science and the United Nations Sustainable Development Goals. Nat. Sustain. 2019, 2, 922-930. [CrossRef]

33. Badan Pusat Statistik. Kabupaten Bangka Provinsi Bangka Belitung dalam angka 2019; BPS Provinsi Kepulauan Bangka Belitung: Bangka Belitung, Indonesia, 2019.

34. Pak, A.A. Interview with Pak Adi A, Farmer, Member of Local Farmer Group Involved in the Present Study. Interview Conducted on July 2018, interview by Maftukhah, R., Mentler, A., written translation by Maftukhah, R., Murtiningrum, M., Ngadisih, N. Unpublished Work.

35. Pak, N. Interview with Pak Nunung, Farmer, Member of Local Farmer Group Involved in the Present Study. Interview Conducted on July 2018, interview by Maftukhah, R., Mentler, A., Keiblinger, K.M., written translation by Maftukhah, R. Unpublished Work.

36. Bouma, J. Reaching out from the soil-box in pursuit of soil security. Soil Sci. Plant Nutr. 2015, 61, 556-565. [CrossRef]

37. Becker, B. Sustainability Assessment: A Review of Values, Concepts, Methodological Approaches; CGIAR: Washington, DC, USA, 1997.

38. Maftukhah, R.; Mentler, A.; Murtiningrum, M.; Ngadisih, N.; Gartner, M.; Hood-Nowotny, R.; Kral, R.M.; Keiblinger, K.M. Soil amendments for re-habilitation after tin mining: A case study on crop yields and drought stress. in preparation.

39. Pak, A.A. Interview with Pak Adi A., Farmer, Member of Local Farmer Group Involved in the Present Study. Interview Conducted on 1 August 2019, interview by Ngadisih, N., Kral, R.M., written translation by Murtiningrum, M. Unpublished Work.

40. Pak, N. Interview with Pak Nunung, Farmer, Member of Local Farmer Group Involved in the Present Study. Interview Conducted on 1 August 2019, interview by Ngadisih, N., Kral, R.M., written translation by Murtiningrum, M. Unpublished Work.

41. Pak, A.B. Interview with Pak Adi B, Farmer, Neighbour to the Experimental Field Site, but not Actively Involved in the Present Study. Interview Conducted on 29 July 2019, interview by Murtiningrum, M., Kral, R.M., written translation by Murtiningrum, M. Unpublished Work.

42. Matthys, M.-L.; University of Bern, Interdisciplinary Center for Gender Research, Bern, Switzerland. Personal Communication, 2 July 2020.

43. EPA. Handbook for Citizen Science. Quality Assurance and Documenatation; United States Environmental Protection Agency: Washington, DC, USA, 2019.

44. Keiblinger, K.M.; Kral, R.M. Sustainable intensification of agricultural production: A review of four soil amendments. Bodenkultur 2018, 69, 141-153. [CrossRef]

45. Eroglu, N.; Emekci, M.; Athanassiou, C.G. Applications of natural zeolites on agriculture and food production. J. Sci. Food Agric. 2017, 97, 3487-3499. [CrossRef]

46. Beza, E.; Steinke, J.; van Etten, J.; Reidsma, P.; Fadda, C.; Mittra, S.; Mathur, P.; Kooistra, L. What are the prospects for citizen science in agriculture? Evidence from three continents on motivation and mobile telephone use of resource-poor farmers. PLoS ONE 2017, 12, e0175700. [CrossRef] [PubMed]

47. Lawrence, A. Introduction: Learning from Experiences of Participatory Biodiversity Assessment. In Taking Stock of Nature: Participatory Biodiversity Assessment for Planning Policy and Practice; Lawrence, A., Ed.; Cambridge University Press: Cambrige, UK, 2010; ISBN 978-0-521-87681-0.

48. Pak, M. Interview with Pak Maman, Farmer, Member of local Farmer Group Involved in the Present Study. Interview Conducted on 29 July 2019, interview by Murtiningrum, M., Kral, R.M., written translation by Murtiningrum, M. Unpublished Work.

49. Sumberg, J.; Okali, C. Farmer's Experiments: Creating Local Knowledge; Rienner: Boulder, CO, USA, 1997; ISBN 9781555876746.

50. Van Veldhuizen, L. Farmers' Research in Practice: Lessons from the Field; Intermediate Technology Publishing: London, UK, 1997; ISBN 1853393924.

(C) 2020 by the authors. Licensee MDPI, Basel, Switzerland. This article is an open access article distributed under the terms and conditions of the Creative Commons Attribution (CC BY) license (http://creativecommons.org/licenses/by/4.0/). 